Webb, M. (1953). Science, 118, 607.

Webb, M. \& Nickerson, W. J. (1956). J. Bact. 71, 140.

Weber, M. W. \& Swartz, M. N. (1960). Arch. Biochem. Biophys. 86, 233.

Winder, F. G. \& Denneny, J. M. (1956). J.gen. Microbiol. 15,1 .

Winder, F. G. \& Denneny, J. M. (1957). J. gen. Microbiol. 17, 573.
Winder, F. G. \& Denneny, J. M. (1959). Nature, Lond., 184, 742.

Winder, F. G., O'Hara, C. \& Ratledge, C. (1961). Biochem. $J .80,21 P$.

Wyatt, G. R. (1951). Biochem. J. 48, 584.

Yanofsky, C. (1954). J. Bact. 68, 577.

Yoshida, A. \& Yamataka, A. (1953). J. Biochem., Tokyo, 40, 85 .

Biochem. J. (1962) 82, 108

\title{
Iodine Metabolism in the Thyroid Gland of the Rat
}

\author{
By ROSALIND PITT-RIVERS \\ National Institute for Medical Research, Mill Hill, London, N.W. 7
}

(Received 2 June 1961)

The steps that lead from the concentration of iodide by the thyroid gland to the formation of the thyroid hormones thyroxine and $3,5,3^{\prime}$-tri-iodothyronine are not yet fully understood. It is generally held that 3-monoiodotyrosine is the first organic iodo-compound formed. In the normal gland, much of this is rapidly converted into diiodotyrosine.

The suggestion of Harington \& Barger (1927) that thyroxine was formed in the thyroid by a coupling reaction between two molecules of diiodotyrosine has not been seriously disputed. However, the biosynthetic mechanism whereby triiodothyronine is formed is still a matter of debate. Gross \& Pitt-Rivers (1953) suggested that it might arise by a partial deiodination of thyroxine, but they produced no evidence in support of this hypothesis. Roche, Michel, Michel \& Lissitzky (1952) had failed to demonstrate any deiodination of thyroxine by thyroid slices in vitro, although they found that in the same conditions iodide was readily obtained from both the iodotyrosines. They concluded that the biosynthesis of tri-iodothyronine probably involved coupling between one molecule each of mono- and di-iodotyrosine.

The likelihood that monoiodotyrosine is the precursor of di-iodotyrosine in thyroglobulin is strongly supported by the work of Taurog, Tong \& Chaikoff (1958), who showed that at early time intervals after a single injection of ${ }^{131} \mathrm{I}$ in rats the monoiodotyrosine ${ }^{131} \mathrm{I}$ content of the thyroid hydrolysates rose rapidly and thereafter fell to a final concentration of about $15 \%$ of the total ${ }^{131} \mathrm{I}$ of the thyroid gland. The radioactivity in di-iodotyrosine reached a maximum after that in monoiodotyrosine had passed its peak, and remained at a concentration of over $40 \%$ of the total ${ }^{131} \mathrm{I}$ for many hours; $75 \mathrm{hr}$. after the injection there was only a slight fall in the radioactive di-iodotyrosine concentration although the radioactive thyroxine content of about $14 \%$ of the total 131I had reached a maximum value 25-30 hr. after the injection. These authors did not investigate tri-iodothyronine in their thyroid hydrolysates.

The high monoiodotyrosine ${ }^{131} \mathrm{I}$ to di-iodotyrosine ${ }^{131}$ I ratios in the thyroid found by Taurog et al. (1958) soon after administration of ${ }^{131}$ I were not observed by Bois \& Larsson (1958); they were unable to detect any changes in the ratio of radioactive monoiodotyrosine to di-iodotyrosine in hydrolysates of rat thyroid $30 \mathrm{~min}$. to 7 days after injection of ${ }^{131} \mathrm{I}$. The incorporation of ${ }^{131} \mathrm{I}$ into thyroxine and tri-iodothyronine increased with time. Further, the ${ }^{131}$ I content of both the iodothyronines rose when the animals were fed on an iodine-deficient diet, but the increase was much more pronounced for tri-iodothyronine than for thyroxine. Since the glands of the iodine-deficient animals contained more radioactive monoiodotyrosine than those of animals on the basic diet, it was concluded that tri-iodothyronine arose from coupling of the two iodotyrosines.

Plaskett $(1961 a, b)$ investigated the distribution of ${ }^{131} \mathrm{I}$ in the two rings of thyroxine and tri-iodothyronine obtained from hydrolysates of thyroids of rabbits injected with ${ }^{131} \mathrm{I} ; \mathbf{2 4} \mathrm{hr}$. after the injection, the specific radioactivity of iodine was equal in both rings of both these amino acids. $\mathrm{He}$ suggested that his findings were compatible with thyroxine being the biological precursor of triiodothyronine.

Feuer \& Vekerdi (1957) and Feuer (1959) found that up to $6 \mathrm{hr}$. after injection of ${ }^{131} \mathrm{I}$ into rats the radioactivity in tri-iodothyronine exceeded that in thyroxine, and fell as that of the thyroxine rose. They suggested that tri-iodothyronine was the pre- 
cursor of thyroxine, but they did not indicate whether this was the only biological mechanism for thyroxine production.

The experiments to be described were undertaken in an attempt to resolve these conflicting findings.

\section{MATERIALS AND METHODS}

Male hooded rats, weighing about $150 \mathrm{~g}$., were fed on diet $41 \mathrm{~B}$ (Bruce, 1958), and received tap water $a d$ lib.

${ }^{131} \mathrm{I}$ as $\mathrm{Na}^{131} \mathrm{I}$ was obtained from The Radiochemical Centre, Amersham, Bucks. Doses (10-50 $\mu \mathrm{c}$ ) were injected intraperitoneally in $0.2 \mathrm{ml}$. of $0.9 \% \mathrm{NaCl}$ soln. in those animals which were killed $30 \mathrm{~min}$. to $8 \mathrm{hr}$. after injection; otherwise the injections were given subcutaneously. Groups of animals were killed with chloroform $0.5,1,2,4,6,8,14$, $16,18,21,24,47$ and $48 \mathrm{hr}$. after the injections. The thyroids were rapidly removed and counted for percentage uptake of the dose in a ring counter described by Campbell, Cuthbertson, Matthews \& McFarlane (1956). They were then cut with scissors and hydrolysed with a mixture of pancreatin and trypsin in $0.2-0.3 \mathrm{ml}$. of $0.2 \mathrm{M}$-tris, $\mathrm{pH} 8.4$, for 24-28 hr. at $37^{\circ}$ with shaking. Portions of the hydrolysates were applied to $2 \mathrm{~cm}$. Whatman no. 1 paper strips, together with carrier iodide, mono- and di-iodotyrosine, thyroxine and tri-iodothyronine. The chromatograms were developed in butan-1-ol-dioxan-aq. $2 \mathrm{~N}-\mathrm{NH}_{3}$ soln. (4:1:5), or in butan-1-ol equilibrated with $2 \mathrm{~N}$-acetic acid, by the ascending technique. The position of iodide on the strips was revealed with palladium chloride, $0.1 \mathrm{M}$ in water; that of the iodinated amino acids with ninhydrin, $0.15 \%$ in $50 \%(v / v)$ ethanol-water. The spots were cut from the paper and the radioactivity was counted in a well-type scintillation counter. The origin spot was also counted to ascertain the amount of unhydrolysed or partially hydrolysed material present. If this exceeded $10 \%$ of the total radioactivity, the chromatograms were discarded; it generally amounted to $6-8 \%$ of the total radioactivity. Iodide, mostly produced as an artifact during hydrolysis, was $7-10 \%$ of the total radioactivity.

\section{RESULTS}

Uptake of ${ }^{131} \mathrm{I}$. The uptake of ${ }^{131} \mathrm{I}$ by the thyroid gland reached a maximum value of $16-20 \%$ of the dose about $16 \mathrm{hr}$. after the injection, and fell to $6 \%$ at $48 \mathrm{hr}$.

Distribution of ${ }^{131} \mathrm{I}$ between the iodoamino acids. The distribution of ${ }^{131} \mathrm{I}$ between the iodotyrosines and iodothyronines is shown in Fig. 1 . The numbers of animals used in each group were: $0.5 \mathrm{hr} .2$; $1 \mathrm{hr}$., 5 ; 2 hr., 6 ; 4 hr., 6 ; 8 hr., 2 ; 14 hr., 7 ; 16 hr., 2 ; $21 \mathrm{hr}$., 1; $24 \mathrm{hr}$., 7; $47 \mathrm{hr}$., 3; $48 \mathrm{hr}$., 2 . The ${ }^{131} \mathrm{I}$ in monoiodotyrosine reaches a maximum value $30 \mathrm{~min}$. after injection of the ${ }^{131} \mathrm{I}$ and falls fairly rapidly during the next $8 \mathrm{hr}$.; thereafter it falls slowly to about $15 \%$ of the total ${ }^{131}$ I at $48 \mathrm{hr}$. The ${ }^{131} \mathrm{I}$ in di-iodotyrosine reaches a maximum value of $45 \%$ of the total $2-4 \mathrm{hr}$. after the injection and remains at this value up to $48 \mathrm{hr}$. The ${ }^{131} \mathrm{I}$ in tri- iodothyronine and thyroxine reach maximum values of 2.8 and $14 \%$ of the total 6 and $14 \mathrm{hr}$. after the injection respectively. At no time interval studied did the radioactivity in tri-iodothyronine exceed that in thyrosine, although the ratio of radioactivity in tri-iodothyronine to thyroxine was higher at the early time intervals.

When the percentage distribution of ${ }^{131}$ I among the labelled compounds has approached isotopic equilibrium, i.e. $48 \mathrm{hr}$. after the injection of ${ }^{131} \mathrm{I}$, the concentration ratio for the stable compounds is assumed to be similar to that of ${ }^{131} \mathrm{I}$ in them. Then the ratio of di-iodotyrosine to monoiodotyrosine is 45:15, and that of thyroxine to tri-iodothyronine is $14: 2 \cdot 8$. Since the total amount of stable iodine in these glands was not determined, only relative specific activities of the different compounds have been estimated. An average thyroid weight of $10 \mathrm{mg}$. was used in all the calculations. By multiplying the percentage of injected radioactivity in di-iodotyrosine by 3 , the estimated relative specific activities of the two iodotyrosines can be plotted. This is shown in Fig. 2.

Similarly, the estimated relative specific activities of thyroxine and tri-iodothyronine are obtained by multiplying the percentage of injected radioactivity in thyroxine by 5 (Fig. 3). In Figs. 2 and 3, each value represents a single animal. From Fig. 2, it is clear that the estimated specific activity of monoiodotyrosine is much higher at an early time interval after injection of ${ }^{131}$ I than that of diiodotyrosine, and falls rapidly as more di-iodo. tyrosine is formed. The estimated specific activity of tri-iodothyronine is higher than that of thyroxine, up to about $8 \mathrm{hr}$. after administration of ${ }^{131} \mathrm{I}$, but does not fall with the rise in ${ }^{131} \mathrm{I}$ in thyroxine (Fig. 3). The estimated specific activities of the two compounds are approximately equal about $24 \mathrm{hr}$. after injection of ${ }^{131} \mathrm{I}$.

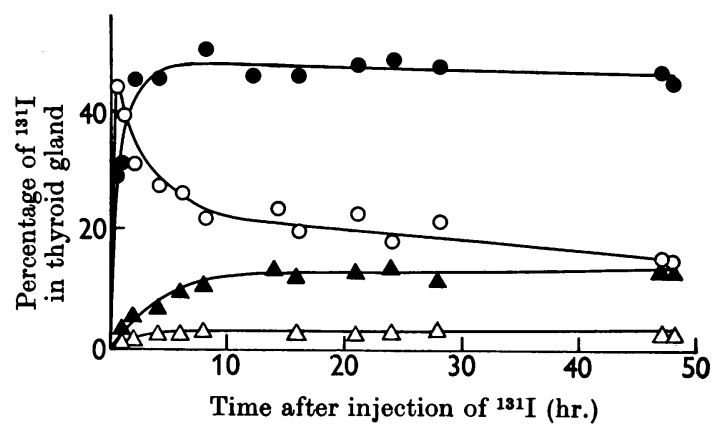

Fig. 1. Distribution of ${ }^{131}$ I between monoiodotyrosine (O), di-iodotyrosine $(\Theta)$, thyroxine $(\Delta)$ and tri-iodothyronine $(\triangle)$ in hydrolysates of rat thyroid gland, $30 \mathrm{~min}$. to $48 \mathrm{hr}$. after injection of ${ }^{131} \mathrm{I}$. 


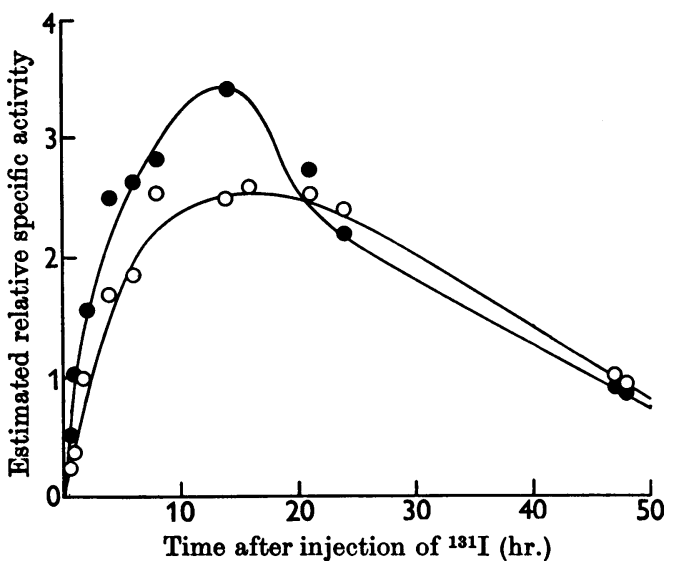

Fig. 2. Estimated relative specific activities of monoiodotyrosine $(O)$ and di-iodotyrosine $(O)$ in hydrolysates of rat thyroid gland, $30 \mathrm{~min}$. to $48 \mathrm{hr}$. after injection of ${ }^{131}$.

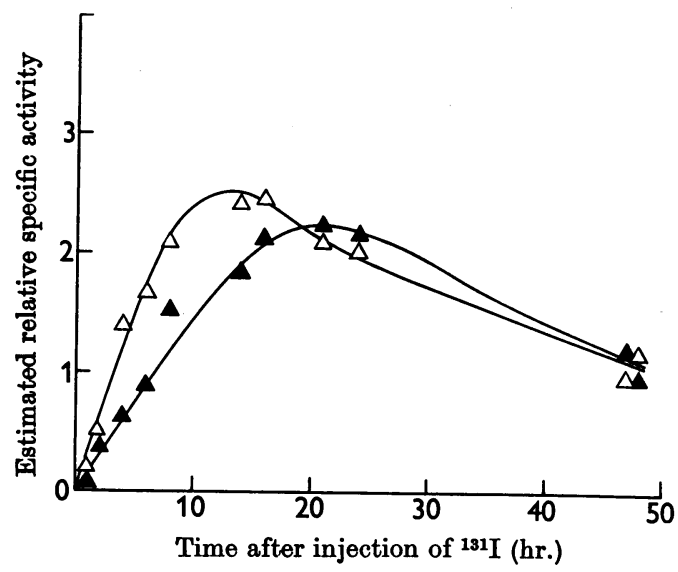

Fig. 3. Estimated relative specific activities of thyroxine $(\Delta)$ and tri-iodothyronine $(\triangle)$ in hydrolysates of rat thyroid gland, $30 \mathrm{~min}$. to $48 \mathrm{hr}$. after injection of ${ }^{131} \mathrm{I}$.

\section{DISCUSSION}

The present findings relating to monoiodotyrosine, di-iodotyrosine and thyroxine are in complete agreement with those of Taurog et al. (1958). There is a very rapid incorporation of ${ }^{131} \mathrm{I}$ into monoiodotyrosine, and as the percentage of ${ }^{131} \mathrm{I}$ in this compound begins to fall, that in di-iodotyrosine reaches its plateau. The relative specific activity data shown in Fig. 2 support the hypothesis that monoiodotyrosine is the precursor of di-iodotyrosine.

If it is assumed that the iodinated compounds under discussion are homogeneous with respect to turnover, tri-iodothyronine could not have arisen by partial deiodination of thyroxine, since its estimated specific activity was greater than that of thyroxine before the latter reached its maximum (cf. Zilversmit, Entenman \& Fischler, 1943). Plaskett's (1961 $b$ ) suggestion that it may be formed by this mechanism is not substantiated. This author studied the ${ }^{131} \mathrm{I}$ in the thyronine rings of the two iodothyronines $24 \mathrm{hr}$. after administration of 131I. By this time, both compounds have almost reached isotopic equilibrium in the rat thyroid gland. Whether this is so in the rabbit thyroid is not known. If isotopic equilibrium has been approached, any differences in the specific radioactivities of the two compounds, which might reveal a precursor-product relationship, will have disappeared.

The present experiments have not confirmed Feuer's (1959) observation that soon after injection of ${ }^{131} \mathrm{I}$ in the rat the radioactivity in tri-iodothyronine exceeds that in thyroxine. However, the estimated specific activity of tri-iodothyronine is higher than that of thyroxine for a few hours. Although these findings do not preclude the possibility that tri-iodothyronine is the precursor of thyroxine, a simpler explanation is that tri-iodothyronine is indeed formed by the coupling of mono- and di-iodotyrosine; at time intervals when the specific activity of monoiodotyrosine is higher than that of di-iodotyrosine, it might be expected that the specific activity of tri-iodothyronine would be higher than that of thyroxine. It is concluded that monoiodotyrosine is the precursor of di-iodotyrosine; that both thyroxine and tri-iodothyronine are formed by a coupling mechanism from the iodotyrosines and that neither thyroxine nor tri-iodothyronine gives rise to the other in the thyroid gland.

\section{SUMMARY}

1. Estimations have been made of ${ }^{131} \mathrm{I}$ incorporated into monoiodotyrosine, di-iodotyrosine, thyroxine and tri-iodothyronine of the thyroid gland from $30 \mathrm{~min}$. to $48 \mathrm{hr}$. after injection of ${ }^{131} \mathrm{I}$.

2. At early time intervals the estimated specific activity of monoiodotyrosine exceeds that of diiodotyrosine.

3. The total radioactivity in thyroxine exceeded that in tri-iodothyronine at all time intervals studied, but the estimated specific radioactivity of the latter compound was higher up to $8 \mathrm{hr}$. after injection of ${ }^{131} \mathrm{I}$.

4. The mechanism of tri-iodothyronine biosynthesis is discussed.

The author wishes to thank Dr N. S. Halmi and Dr Daniel Steinberg for much helpful discussion during this work. 


\section{REFERENCES}

Bois, I. \& Larsson, L.-G. (1958). Acta endocr., Copenhagen, 28, 262.

Bruce, H. M. (1958). Stud. Fertil. 9, 90.

Campbell, R. M., Cuthbertson, D. P., Matthews, C. M. E. \& McFarlane, A. S. (1956). Int. J. appl. Radiat. 1, 66.

Feuer, G. (1959). Biochem. J. 73, 349.

Fever, G. \& Vekerdi, L. (1957). Acta physiol. hung. 13, 301.

Gross, J. \& Pitt-Rivers, R. (1953). Biochem. J. 53, 652.
Harington, C. R. \& Barger, G. (1927). Biochem. J. 21, 169.

Plaskett, L. G. (1961 a). Biochem. J. 78, 649.

Plaskett, L. G. (1961 b). Biochem. J. 78, 657.

Roche, J., Michel, R., Michel, O. \& Lissitzky, S. (1952). Biochim. biophys. Acta, 9, 161.

Taurog, A., Tong, W. \& Chaikoff, I. L. (1958). Endocrinology, 62, 646.

Zilversmit, D. B., Entenman, C. \& Fischler, M. C. (1943). J. gen. Physiol. 26, 325.

Biochem. J. (1962) 82, 111

\title{
The Separation of Iodinated Tyrosines and Thyroxine from Serum
}

\author{
BY ROSALIND PITT-RIVERS AND B. I. SACKS* \\ National Institute for Medical Research, Mill Hill, London, N.W. 7
}

(Received 2 June 1961)

Anion-exchange resins have been used for the separation of the iodotyrosines and iodothyronines from serum proteins. Blanquet, Meyniel, Mounier, Stoll \& Maraud (1957), Blanquet, Meyniel, Mounier \& Tobias (1957) and Meyniel, Blanquet, Mounier \& Estibotte (1958) used aqueous or aqueous ethanolic hydrochloric acid for the elution of iodinated compounds from Dowex 1 or 2 but the separations achieved were incomplete. Galton \& Pitt-Rivers (1959) used sodium acetate buffers for elution of the iodotyrosines and $50 \%(\mathrm{v} / \mathrm{v})$ acetic acid for the elution of thyroxine and tri-iodothyronine from Dowex 1 (X 2). Lissitzky \& Lasry (1958) used aqueous formic acid for elution of all the organic iodo-compounds from Dowex I (X 8). They obtained good separation of the iodotyrosines, but, as they pointed out, the volumes of aqueous formic acid required to elute each compound were large, and formic acid is difficult to evaporate to dryness in vacuo.

A further problem connected with the analysis of serum on anion-exchange resins is concerned with the competitive binding of iodothyronines by the serum proteins and the active sites of the resin. As a result considerable amounts of thyroxine and triiodothyronine may escape from the columns unless unmanageably long ones are used.

This paper describes modifications of the technique of Galton \& Pitt-Rivers (1959) whereby the iodotyrosines and iodothyronines are separated with different concentrations of aqueous acetic acid. It also describes the partial enzymic hydrolysis of

* Attached to the Medical Unit, University College Hospital Medical School, London, W.C. 1. In receipt of a grant from the British Empire Cancer Campaign. serum, which inactivates its thyroxine-binding properties and permits the loading of relatively large quantities on to a column of only $3 \mathrm{~cm} . \times 1 \mathrm{~cm}$.

\section{MATERIALS AND METHODS}

Resin. Since variable results were obtained with commercial grades of resins, analytical-grade Dowex resin A.G. 1 (chloride form; X 2; 200-400 mesh), manufactured by the Bio-Rad Corp., was used. In most experiments it was converted into the acetate form by washing with saturated sodium acetate solution until chloride-free; a few washings with $0 \cdot 2 \mathrm{M}$-sodium acetate gave equally good results. Excess of acetate was removed with deionized water, which was also used to prepare the reagents. Columns $3 \mathrm{~cm}$. long and $1 \mathrm{~cm}$. in diameter were used.

Serum. Human serum was used for most of the experiments, but rabbit or rat serum gave the same results.

${ }^{131}$ I-Labelled compounds. ${ }^{131}$ I-Labelled thyroxine and triiodothyronine were obtained from Abbott Laboratories, Oak Ridge. ${ }^{131}$ I-Labelled mono- and di-iodotyrosine were prepared from hydrolysates of rat thyroid gland by paperchromatographic separation in butan-1-ol equilibrated with $2 \mathrm{~N}$-acetic acid and elution with aq. $\mathrm{N}-\mathrm{NH}_{3}$ soln. at $3^{\circ}$ (Pitt-Rivers, 1962). Fresh aqueous solutions of the labelled iodotyrosines were contaminated with about $5 \%$ of iodide, and the amount of iodide increased within 1 or 2 weeks to about $15 \%$, even on storage in the cold. ${ }^{131}$ I-Labelled 'thyroglobulin' was prepared by homogenizing two or three rat thyroid glands in deionized water (about $5 \mathrm{ml}$.) and filtering through Schleicher and Schüll paper no. 575. The rats were injected with $20-50 \mu \mathrm{C}$ of ${ }^{131} \mathrm{I} 16 \mathrm{hr}$. before removal of the thyroid.

Eluents. Dilutions of aqueous acetic acid were used except for thyroglobulin, which was eluted with $0.2 \mathrm{M}$ acetate buffer, pH 3.6 (sodium acetate, $0.5 \mathrm{ml}$.; acetic acid, $9.5 \mathrm{ml}$.). Each fraction consisted of $3 \mathrm{ml}$., since this was the greatest volume that could be counted in the well-type scintillation counter. 